\title{
FOOD, TECHNOLOGY,
}

\section{AND TRANSLOCAL TRANSFORMATIONS OF TASTE}

\author{
Industrial and Processed Food in Yucatán
}

\section{INTRODUCTION}

In this paper I argue that food-related transformations in Mexico in general, and the Yucatán in particular, have reflected those occurring at the same time in other countries from the end of the nineteenth century to date. This synchronous occurrence has to be conceptually explained by the general processes that spawn global-local ('glocal'), and translocal connections that have been instrumental in the transference both of new cooking instruments, appliances and ingredients. We need to qualify the analysis of global-local relations to destabilize the binary opposition between global processes and local effects-a dichotomy that emphasizes the analysis of vertical relations between societies, either top-down or from the bottom up. In order to do this, I believe that we need to flesh out the concept of translocality, now used by many authors in the fields of sociology, anthropology, and political sciences. In my view, its use has thus far been mostly suggestive. I find the concept 'translocality' useful for exploring horizontal relations between groups, supplementing the multiple vertical processes. Here, I argue that these complex articulations

1. A different, earlier, and shorter version of this paper was presented at the International Forum for US Studies at the University of Illinois in Urbana-Champaign on February 14, 2019. I thank Jane Desmond and Virginia Dominguez for their invitation to share my work, and all the attendees for their comments and feedback. I also thank the two anonymous reviewers for their comments and observations. 
steer change in often unexpected directions and occur in different scales of social, cultural and political articulations expressed though the preference of processed, industrially produced food ingredients.

As Sue Shephard shows, food results from human intervention aimed at processing ingredients into meals, whether for immediate personal intake or for its preservation. When preserved, it can be consumed later, often by someone different from the original grower or packager, sometime in the future and at the same or some other location. The modes of intervention changed in meaningful ways during the nineteenth century when, as Yves Segers points out, large European firms, specialized in industrialized food processing and preservation, displaced earlier efforts controlled by local and regional producers, such as small factories tied to farmers and other primary producers (2009: 13). The expansion of US corporations into the UK during the end of the nineteenth and the first half of the twentieth century shaped views on modernization and, importantly, as Ted Collins argues, the promise of safe industrialized food products. US Food Corporations originally developed advertising alien to those of their British counterparts (2009: 162). Today, industrialized food has come under close scrutiny and severe criticism because the industrial diet is considered responsible for the global rise of many health issues (Winson 2014). In Simon N. Williams and Marion Nestle's volume Big Food, the authors examine this

One World The Americas Everywhere diet's effects of pandemic obesity and related health problems. The use of chemical preservatives, color and flavor enhancers is now believed responsible for the rising numbers of allergies and intolerance to food ingredients (Arnot 2018; Blythman 2015; Ettlinger 2007; Taubes 2016). However, after two centuries of the everyday presence of industrial food products in home kitchens, as well as in a vast array of eating places, most people consume them not caring about the origins or effects of the different additives, as illustrated by the following story.

In January 2019, a friend posted a meme on Facebook depicting an extravagant culinary invention, supposedly concocted under the influence of cannabis. A mutual friend responded with a picture and description of a sandwichón, a popular Yucatecan meal 
she had encountered during her visit to Mérida in 2019. This dish looks like, and is a remnant of, nineteen fifties and sixties cooking, when 'modern' housewives were supposed to cook using space-age foodstuffs; that is, industrially processed and preserved edible products. Today, the sandwichón has become rather baroque. More than 50 years ago women prepared it with layers of lengthwise-sliced white bread on which they would spread a mixture of cream cheese, whipping cream and shredded chicken. Nowadays, it is common to stuff the layers with strawberry marmalade, baked ham, cheese, and finish it with a frosting of cream cheese and whipping cream. The final decoration may be some ground cinnamon, or stripes of ham and cheese, or whatever else the cook is inspired to add. Most ingredients are industrially processed and preserved. In decades past, a sandwichón was prepared for children's birthdays, or for dinner on Christmas or New Year's Eve. Today, people celebrating any event at an office may order it from corner and convenience stores. In downtown Mérida, when people feel the pangs of hunger at midday, they can find a slice of sandwichón to satisfy their cravings.

In Mérida, at the end of the 1960s, there was a local cookbook dedicated to buffets and party meals that included recipes for cocktails and meals prescribing a generous use of canned ingredients (Velázquez de Esquivel 1970). It was a time when tin and saltpeter shaped the taste of "modernity." This is true for the United States as much as it was for Yucatán, for Mexico, and for most places around the world. House cooks readily accepted the values of efficiency, convenience, and hygiene that defined processed foods. Both Elizabeth B. Silva and Elizabeth Shove describe how this disposition became common in England at around the same time. In turn, Christina Ward shows that processed foods were pressed upon the everyday diet of families through corporate advertising.

Books such as James Lileks' satirically titled The Callery of Regrettable Foods and Ward's American Advertising Cookbooks illustrate the effects of publicity campaigns encouraging modern housewives to cook with processed, canned, and other preserved foods. Large agribusiness corporations, canners and retailers pushed their recipes into cookbooks and leaflets distributed in supermarkets 
or accompanying new appliances. These recipes intimated that the inclusion of industrially processed foods into everyday meals was the housewife's badge of modernity. Recipes were displayed as free of ethnic or national cultural backgrounds even though, internationally, they represented the style of food consumption associated with white, Anglo culture in the United States. Similar pamphlets and cooking suggestions were available in Spanish in Yucatán, stressing values such as convenience, hygiene, practicality and, importantly, frugality. They highlighted the benefits, the time-saving value of meals for housewives-women who must cook for their families, and for their husbands' co-workers, while they also work outside the home, and keep the cost of meals low.

\section{GLOBAL-LOCAL AND TRANSLOCAL CONNECTIONS (AS SEEN THROUGH FOOD)}

There are many discordant and complementary approaches to Globalization. Works by Marshall McLuhan and Bruce R. Powers, June Nash, Alain Touraine, Eric Wolf, and Immanuel Wallerstein, to name only a few, emphasize either global connectivity or the process of social and cultural homogenization. In food studies, some write of 'Coca-globalization' and the Macdonaldization of the world (Foster 2008; Leatherman and Goodman 2005). That is, for some authors, the term "globalization" captures the fear that all food and drinks and, by extension, all cultural practices and values in the world are becoming the same. Alternatively, others prefer

One World

The Americas

Everywhere

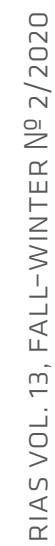
to emphasize the local, heterogenizing processes whereby local appropriations and adaptations lead to the emergence of difference. Castells, Edelman and Friedman, for example, analyze local, ethnic identity and other special-interest social movements as results of this process. For my part, I have subscribed, since the 1990s, to the view advanced by Roland Robertson in his work on globalization and glocalization that we witness the simultaneous existence of homogenizing and heterogenizing forces and tendencies. Neither of them can be ever complete, because they are dynamic, fluid and in continuous interaction. Robertson first described this complex articulation in 1992, and in 1995 he adopted the term glocalization from Japanese business studies. Arjun Appadurai offered shortly after an anthropological, supple- 
mentary approach. Below, I will argue that we need to qualify the analysis of global-local relations to destabilize the binary opposition between global processes and local effects-a dichotomy that emphasizes the analysis of vertical relations between societies, either from the top-down or from the bottom up (Ayora-Díaz 2007, 2013, 2017; Ayora-Díaz, et al. 2016).

Contemporary societies are fluid, dynamic, and unstable. Mobility, as Appadurai, Marc Augé, Nina Glick Schiller and Noel B. Salazar, John Urry and others have suggested, is one of their defining traits: It is the mobility of people, commodities (including those that are used in cooking), technologies, money, and discursive constructions that mark global contemporary society. The latter are often instrumental in the shaping of complex social and cultural imaginaries. This dimension of global flows and frictions is important for understanding the first component of translocality: each social group is fluid, its members are constantly changing, and it is simultaneously part of other groups and processes taking place elsewhere in the world. In terms of food, many ingredients and cooking technologies have been introduced in every society following contact with other groups with culinary practices different from their own. Second, these transformations occur at different scales: translocal relations must be considered not only 'below' or in the middle of the global-local. The largest scale, the global, is one in which North Atlantic values have been universalized, and locally adopted and adapted. For example, 'modernity' is not the same in the United States, in Canada, in Mexico, or in different European countries. However, we socially imagine 'modernity' as the shared practices, values, and discourses among these societies. That is, hegemonic societies forge their own translocal connections, even if it is often the metropolis that are connected. A different scale is that of subordinate, colonized societies. They appropriate practices, values and worldviews from the various colonizing states differently and often, at least in certain regards, long accepted a cultural hierarchy that places French cuisine above all others. Subordinated societies also exchange people, ideas, practices, technologies and money, and thus are able to create new and different cultural practices that are common to all of them and, nonetheless, different. Recipes in different Caribbean societies reflect 
these shared practices and still distinguish between the taste of their own and that of other Caribbean cuisines. For example, despite some differences, lechon horneado in Cuba, Puerto Rico, and Yucatán share techniques, technologies and flavors; as does stuffed cheese in the kitchens of Venezuela, Curaçao, Puerto Rico, Yucatán, and Nicaragua, where cooks use Dutch Edam cheese, albeit with different stuffing.

Third, the temporal dimension is also important. Here, I am not proposing we look for or imagine continuities in practice, such as when someone seeks to draw connections between contemporary and pre-Hispanic foodways; instead, we need to locate breaks, ruptures, and discontinuities. Hence, in Yucatán we need to recognize a sedimentation of culinary practices and preferences tied to different moments of colonization and global connection: today's cooking practices of peninsular inhabitants blend food practices used by the Maya with those imposed by (or copied from) the Aztec, who colonized them first, and with those later imposed or copied from Spanish conquerors. Besides, many other cooking and eating practices have merged, during the last five centuries (and especially by the end of the 1800s), the "taste" and culinary "traditions" of immigrants from Caribbean societies, Lebanon, Syria, Korea, China, Italy, France, Germany, and, more recently, the US and Canada. Through time, different social, political, and economic changes facilitated or prevented the flow of edible commodities, cooking technologies, people, money and ideas. In each period

One World The Americas Everywhere of rupture there were new additions that made culinary preferences discontinuous despite superficial appearances of continuity.

Fourth, when analyzing translocal processes we must avoid assuming that horizontality means equality or harmony. The elites of a subordinated society may seek a dominant position over other subordinated groups and sustain the conviction that one's own social organization, culture or culinary practices are better than those of the others. For example, during the 1990s, I conducted research unrelated to food in the state of Chiapas, Mexico. The dominant imagination held all Indigenous groups as equally subordinated to settler society. Yet, once, travelling with a Tzeltal-speaking cultural broker, I asked him about the food we just ate in his village. When I inquired about other foods available in the region, 
he rejected the notion that he would eat the food of the Chamula, Tzotzil-speaking people. From his point of view, Chamula's food was akin to animals feed. Racism, elitism and discrimination are regularly extended to food and food-related practices at all levels of the social scale.

Fifth, and lastly, translocal connections require significant social actors, that is, individuals endowed with the authority to mediate between one group and another. In Friction, Anna Tsing has shown how different subjects mediate and transform practices and discourses as they move from supranational agencies, to nation-states, to agencies in charge of their dissemination, and the local appropriation by different local groups. At the turn of the twentieth century, local elites embraced the notion of "progress" to encourage the invention of new production technologies, turning Yucatán into a showcase of "progress" (today's modernity) for the whole of Mexico (Zayas Enríquez 1908).

\section{TRANSLOCALITY AND CULINARY-GASTRONOMIC TECHNOLOGIES}

Translocal exchanges also help establish gastronomic hierarchies. This has been the case for French cuisine, which until recently was recognized as the universal paradigm of haute cuisine (Ferguson 2004; Trubek 2000). This seems to be the case even when some vernacular adaptations occur, such as during the nineteenth century imagination of a nationalist Mexican cuisine. As Sarah Bak-Geller Corona has shown, at that time Mexican newspaper writers appropriated the notion of bon goût from the French while at the same time they nationalized it. For example, in the Yucatán, the preface to a book on "Maya" cooking affirms the equivalence between Maya and French cuisines as, the author argues, the Maya gave as much importance to sauces as the French do (Maldonado Castro 2000). Regardless of the veracity of this affirmation, I find the author's comparison to be an implicitly acknowledgment of the superiority of French cooking.

As I have discussed elsewhere, during the nineteenth century, members of the regional elite traveled to the United States, to different Caribbean countries and to England and France. There, they engaged in trade or sought an education. Yet, from 
those places they also imported new culinary preferences that allowed regional cuisine to be represented as "cosmopolitan" (Ayora-Díaz 2012). In 1889, for example, Manuela Navarrete Arce, from the city of Valladolid, in Yucatán, published a cookbook in which, among other things, she borrowed from European etiquette books to give advice regarding proper table manners. Her cookbook was published at a moment of economic prosperity based on the success of the henequen plantation economy in the Yucatán peninsula. It reflects the global-local but also translocal connections, as many Yucatecans travelled to Cuba, Puerto Rico, Venezuela, Colombia, the Dominican Republic, Texas and Louisiana, and the region also received immigrants from those and other countries. Immigrants also imported their taste preferences and gradually plantain, banana leaves, pork, cumin, oregano, capers, olives and olive oil, Seville oranges and limes, as well as root vegetables, became part of Yucatecan cooking. Gradually, these ingredients formed Yucatecan taste.

Taste is not restricted to the aesthetic properties of food, as flavors, aromas, textures and auditory experiences all accompany a meal's visual presentation. Importantly, taste is historically constructed, although this is often bracketed, as it is often perceived as a natural disposition (Ayora-Díaz 2012). However, this disposition changes over time, as food

One World The Americas Everywhere itself changes and consumers change their taste. Culinary 'traditions,' then, change while taste itself changes through the effects of regional supply origins and various technological transformations. Our contemporary diet, as it is now often argued, is one in which processed and hyper-processed foods abound. Their effects are multiple. Some authors, like Williams and Nestle, may stress their detrimental effects on the health of individuals and populations, while others, including writers of popular cookbooks in Yucatán, point at the beneficial effects on the health and way of life of contemporary women. In any case, it is important to examine the ways in which the taste of and for food changes following the increasing use of industrially processed and super-processed foodstuffs. 
In everyday language, 'preserved' and 'processed' are often used interchangeably, and sometimes their meanings overlap. This allows for ambiguity regarding the things we consider edible. Technically, all food is processed; that is, it has undergone some transformation in the hands of a person: she washed, or boiled, or roasted, or fried, or salted, or smoked, or chopped, or shredded, or otherwise modified it. In this broad sense, everything we eat is processed. Preserved food, on the other hand, is food that has been transformed with the purpose of prolonging its edible life. This can be done, for example, by smoking, salting, drying, or pickling. We eat the former, and the latter we keep in jars, cans, clay or ceramic pots or other vessels to eat them at a later time. Shephard has demonstrated how we humans have preserved food by different means for several thousands of years, and the means for preserving it have changed according to the different environments in which people need to store food. That is, if a group lives in the tropics, they have to resort to different preservation techniques than those who live in very cold or hot and dry conditions, such as deserts. In her view, preserving food has at least two advantages: one is that it has historically allowed people to travel, carrying their food and ensuring their physical survival. The other is that in societies hitherto dependent on seasonal availability, different methods of preservation allow members to have food during seasons when it was previously unavailable. It is during the last two hundred years that preservation radically changed, especially when chemists and cooks joined hands in an effort to keep foods edible for a long time. Canning, a technology developed at the end of the eighteenth and beginning of the nineteenth centuries, brought advantages to consumers of preserved foods, and especially soldiers in war, as tin cans could be carried safely from one part of the world to another. However, it also brought a number of disadvantages, such as botulism and heavy metal poisoning, which had to wait for later developments in microbiology and toxicology before being largely eradicated (Zeide 2018).

During the twentieth century the industrialization and mass production of preserved foods reached new heights, primarily in the United States. Industrialization and mass production have 
required the use of ingredients in forms that often remain veiled for the consumer: We don't know how they are preparing the meat for our sausages and Spam, how the ham sold at supermarkets is cured, or how they harvest and select tomatoes that go into the ragout or pesto for our home-cooked pastas. We have no idea as to the chemicals used to enhance the flavor and the color, and to preserve textures in what we eat. Joanne Blythman says that processed food "sits in supermarket shelves in boxes, cartons and bottles" and is "food that had something done to make it more convenient and ready-to-eat" (2015: 1). Of course, "something done" often means the use of synthetic additives, flavor and color enhancers, and stimulants for both our taste and other sensory organs, as well as our appetite. We have all been acquainted with exposés of the food industry. Upton Sinclair's The Jungle, originally published in 1906, is an early and paradigmatic example from the early twentieth century in which he revealed the dark secrets of the meat packing industry in Chicago. Today we have at our disposal an ever-growing list of documentaries, books, and newspaper articles denouncing agribusiness corporations and the food industry in general.

Anthony Winson argues that the United States has played an important part in shaping the dietary regime he calls "industrial diet" (2014: 21). Evidently, the transition to the contemporary diet was led by North Atlantic countries. Canada, England, Germany and France all contributed, along with the US, to this transforma-

One World The Americas Everywhere tion. Industrialization, in Winson's view, is the central characteristic of the contemporary diet, in which, at least since the mid-nineteenth century, the canning industry has played a significant part. In his view, the for-profit economic organization of the processed food industry has been important in degrading the quality of the foods we consume, and subsequent national health problems. He labels the US-led industrial diet as "degraded," and singles it out as one of the main factors leading to obesity and other related illnesses. Like Winson, Anna Zeide also recognizes and analyzes the ties between canning and the growth of the processed food industry.

The use of different synthetic additives also plays an important role in the increasingly questionable image of the food canning and processed food industries. A large taste industry has grown 
in the US and elsewhere, where chemists seek new synthetic elements that can mimic different flavors. Mark Schatzker has described what he calls the "dilution" effect in our meals, which comes from growing large vegetables and animals, and in doing it quickly. During and following World War II, different agencies, including those run by the state, promoted the modification of foods. Agricultural fairs had prizes for those who grew the largest pumpkin, tomato, lettuce, or chicken. Schatzker argues that animals and plants do not have the time to incorporate minerals and other elements found in the soil or in their feed, so that meat comes to taste of "nothing" or a little like "something." The hydroponic production of vegetables has the same effects on taste, aroma and texture. In the face of these changes a field of industrial research has grown seeking to create flavor and color enhancers, so that we can find tastier commercially processed tomato sauces than those we achieve at home when cooking with fresh, 'natural' tomatoes. The literature critical of the food industry is vast. Melanie Warner has demonstrated how the food industry adds different chemicals into our food, making some foods seem almost eternal. Because of the processed food industry and CMOs, what often gets served on our plates are synthetic chemicals destined to prolong shelf life, to enhance color and flavors, to preserve texture, and to provide additional flavor to our food.

In contrast, there are those who would emphasize the benefits of industrially processed and preserved food. They may underline the fact that before the growth in this industry, people were sadly restricted to eating some things during their seasonal harvest. Today our food is free of these constraints. Also, industrially processed and preserved food allows people in different parts of the world to consume fruits, vegetables or meats that would otherwise be unavailable to them. For example, canned pineapple in the northern US during the winter, or peaches in Yucatán at any time. In addition, we are told, canned and other packaged food is hygienic and thus consumers don't need to worry about contamination or the toxicity levelsof these ingredients. Finally, processed foods are convenient. A person may go into a supermarket and buy pre-cooked bacon or pizza to zap in the microwave oven; or pre-marinated meats one only needs to place on the skillet, grill or oven; or canned meats 
to add into stews. In the opinion of different authors, these benefits far outweigh the disadvantages of industrially processed and preserved foods (Laudan 2001; Mcclements et al. 2011; Shewfelt 2017).

\section{PROCESSED TASTE IN YUCATÁN}

A love of technology has long existed in Yucatán (Vargas-Cetina 2017). At the end of the nineteenth century it was Yucatecans who engaged in the invention of a machine to process henequen fiber. Yucatecan entrepreneurs developed one of the densest railroad networks of their time. In 1900, with German technology, Yucatecans inaugurated the first regional brewery in the peninsula, Cervecería Yucateca. In 1905, Galletería Dondé began industrial production of crackers and cookies. By 1950, the company HYSA began producing and selling processed, hydrogenated vegetable oils, including a green oil they marketed as 'olive oil' but which had no olives in it. In turn, recados are multiple blends of spices similar to Indian masalas and Oaxaca moles. They were usually handcrafted by a member of the family, and are difficult, cumbersome to make. In 1913, La Anita began the process of industrialization of recados. Other companies, such as El Yucateco, which emerged in 1968, now compete with La Anita and have managed to gain a share of the regional, national and international market. Today, La Anita produces recados, habanero pepper sauces, and other condiments that are important in the Yucatecan gastronomic canon and, because

One World

The Americas

Everywhere of their scale, they have contributed to homogenizing the taste of Yucatecan food in the region. Many of these recados and sauces list a number of synthetic and processed colorants, stabilizers, and flavor enhancers among their ingredients.

Canning has also been an important industrial activity in Mexico. Herdez began canning in Monterey in 1914. Del Monte began operations in California during the end of the nineteenth century and expanded more fully into Mexico in 1957 (Del Monte is affiliated with ConAgra). Mexican, and of course Yucatecan, supermarkets are flooded with a multitude of canned, jarred, and otherwise packaged ingredients that have been industrially processed. In contemporary society, these products are seen as convenient and important ingredients in domestic pantries. 
The blandness of "natural" foods and the intense colors and flavors of industrially processed and preserved ones has had an impact in the taste of and for the food in Yucatán. Canned products have a rather intense flavor and aroma. Industrially processed foods maintain a place in most pantries. When I have interviewed Yucatecan home cooks, they claim to use them only seldom. Yet, when given permission to check their kitchen shelves, I always find many canned grains, fish, chili peppers, and sauces. In fact, a friend who on account of different food intolerances often claimed to have a 'natural' diet, served us refried black beans that she had reconstituted from a dry powder, and then re-fried. Older friends told me how to 'improve' canned beans by adding dry cubes of chicken broth, rich in monosodium glutamate (MSC).

We need to ask ourselves: What aesthetic values are being staged when one adds a green bright powder to the salad? Does the taste improve, and how? Or, are people indifferent to these effects? Sometimes they seem to be indifferent. For example, at a family meal our host served black beans and pork, a 'traditional' Monday meal in Yucatán. My wife and I found the taste to be 'not quite right.' We told those sitting next to us at the table, but they did not agree with us. After the meal was over and other guests have gone, I asked our host and she confessed that when she saw many more people than she expected she added canned beans. At home we eat canned foods as infrequently as possible, so we could taste that something was not quite right by our standards. The others eat processed foods often and did not find anything unusual.

Restaurant food in Yucatán is undergoing similar changes. Papadzules, a meal made with a sauce of ground pumpkin seeds and epazote, seldom achieves the green color consumers expect. Hence, restaurant chefs and cooks add artificial colorants, sometimes resulting in an intense green that looks radioactive. The pumpkin seeds no longer have a strong taste, either. So, they add chicken bouillon cubes or sour cream, attempting to emulate the 'traditional' flavors of that dish that many Yucatecans still remember. Flavors of different regional dishes like these are changing as the flavor of the natural ingredients gets diluted, and cooks introduce processed ingredients in their kitchens. 
As the taste of Yucatecan food changes, the taste for Yucatecan food changes as well.

PROGRESS, MODERNITY AND FOOD

The Yucatecan regional foodscape is part and parcel of translocal configurations and exchanges. People from different parts of Mexico and the world have moved into Yucatán and brought along their aesthetics, including their food preferences. Furthermore, television channels, social media, newspapers, and radio stations all promote different food choices; department stores and specialized businesses make new cooking technologies available and the market for edible commodities widens as ingredients from different parts of the world become available. Although there is a global-local relation whereby new aesthetic gastronomic codes are disseminated and culinary school promote them, there are also translocal connections that create a negotiated consensus about the different types of good food and good taste of and for food. Different individuals act as promoters of either 'innovation' or 'tradition' leading to their regional coexistence. Thanks to the concerted efforts of a group of local chefs and the city of Mérida administration, the city was included in 2019 in the list of "Creative" cities of UNESCO for its gastronomy. This recognition for "innovation" stands at odds with the efforts of a different set of chefs and restaurateurs who seek to uphold "traditional" Yucatecan food; yet, both

One World The Americas Everywhere groups enrich the regional foodscape.

To conclude: (1) the local understanding of 'progress' and 'modernity' shares a faith in new scientific knowledge and emerging technologies among regional elites. (2) The dissemination of industrially processed and preserved foods has been important in shaping the taste of foods everywhere. Meals cooked with Coca-Cola or Catsup are present in the domestic repertoire in Yucatán just as they continue to be cooked in different regions of the US. Even today, when in Yucatán there is access to good quality olive oils from the Mediterranean, many Yucatecans still long for the flavor added to their ceviche and seafood cocktails by simulated olive oil from HYSA. (3) The intensity of flavors and chemically induced colors in highly processed foods is now 
affecting the cooking and enjoyment of 'traditional' Yucatecan recipes. (4) As younger generations become acquainted with the food of different regions of the world, sometimes imported into Yucatán with the aid of processed and canned ingredients, the taste for Yucatecan food is also changing, as the flavors of exotic meals displace the appreciation for regional flavors. In the end, global-local and translocal relationships are instrumental in explaining the taste and changes in the taste of and for Yucatecan foods.

Steffan Igor Ayora-Díaz Universidad Autónoma de Yucatán Merida, Mexico 
WORKS CITED

Appadurai, Arjun. Modernity at Large. Cultural Dimensions of Globalization. U of Minnesota P, 1996.

Arnot, Charlie. Size Matters: Why We Love to Hate Big Food. Springer, 2018.

Augé, Marc. Por una antropología de la movilidad. Barcelona: Gedisa, 2007.

Ayora-Díaz, Steffan Igor. "Translocalidad y la antropología de los procesos globales: saber y poder en Chiapas y Yucatán." Journal of Latin American and Caribbean Anthroplogy, vol. 12, no. 1, 2007, pp. 134-163. https://doi.org/10.1525/jlca.2007.12.1.134

----- Foodscapes, Foodfields and Identities in Yucatán. CEDLABerghahn, 2012.

------. "Intersections translocales: le cas de la gastronomie yucatèque." Anthropologie et Sociétés, vol. 37, no. 2, 2013, pp. 67-89. https:// doi.org/10.7202/1017906ar

------. "Translocalidad, globalización y regionalismo: cómo entender la gastronomía regional yucateca." Anales de Antropología, vol. 51, no. 2, 2017, pp. 96-105. https://doi-org.tamiu.idm.oclc. org/10.1016/j.antro.2017.03.004

Ayora-Díaz, et al. Cocina, música y comunicación: tecnologías y estética en el Yucatán. Universidad Autónoma de Yucatán. 2016.

Bak-Geller Corona, Sarah. "Gastronomy and the Origins of Republicanism in Mexico." Taste, Politics, and Identities in Mexican Food,

One World

The Americas

Everywhere edited by Steffan Igor Ayora-Díaz. Bloomsbury Academic, 2019, pp. 39-50.

Blythman, Joanne. Swallow This. Serving Up the Food Industry's Darkest Secrets. Fourth Estate, 2015

Castells, Manuel. The Rise of Network Society. Blackwell, 2000.

Collins, Ted. "The North American Influence on Food Manufacturing in Britain, 1880-1939." Exploring the Food Chain: Food Production and Food Processing in Western Europe, 1850-1990, edited by Yves Seger, et al. Brepols, 2009, pp. 153-175

Edelman, Marc. Peasants Against Globalization: Rural Social Movements in Costa Rica. Stanford UP, 1999

Ettlinger, Steve. Twinkie, Deconstructed. My Journey to Discover How the Ingredients Found in Processed Foods Are Grown, Mined 
(Yes, Mined), and Manipulated into What America Eats. Hudson Street Press, 2007.

Ferguson, Priscilla Parkhurst. Accounting for Taste. The Triumph of French Cuisine. U of Chicago P, 2004.

Foster, Robert J. Coca-Globalization. Following Soft Drinks from New York to New Guinea. Palgrave MacMillan, 2008.

Friedman, Jonathan. Cultural Identity and Global Process. Sage, 1994.

Laudan, Rachel. "A Plea for Culinary Modernism: Why We Should Love New, Fast, Processed Food." Castronomica, vol. 1, no. 1, 2001, pp. 36-44. https://doi.org/10.1525/gfc.2001.1.1.36

Leatherman, Thomas L. and Alan Goodman. "Coca-Colonization of Diets in the Yucatán." Social Sciences and Medicine, vol. 61, no. 4, 2005, pp. 833-846. https://doi.org/10.1016/j.socscimed.2004.08.047

Lileks, James. The Gallery of Regrettable Foods. Highlights from Classic American Recipe Books. Random House, 2001.

Maldonado Castro, Roberto. Recetario maya del Estado de Yucatán. Mexico City: CONACULTA, 2000.

McLuhan, Marshall and Bruce R. Powers. The Global Village. Transformations in World Life and Media in the 215t Century. Oxford University Press, 1989.

Mcclements, David Julian, et al. "In Defense of Food Science." Gastronomica, vol. 11, no. 2, 2011, pp. 76-84. https://doi.org/10.1525/ gfc.2011.11.2.76

Nash, June. "Consuming Interests: Water, Rum, and Coca-Cola from Ritual Propitiation to Corporate Expropriation in Highland Chiapas." Cultural Anthropology, vol. 22, no. 4, 2007, pp. 621-639. https://doi.org/10.1525/can.2007.22.4.621

Navarrete Arce, Manuela. La verdadera cocina yucateca. Mérida, 1911; Valladolid, 1889.

Robertson, Roland. Globalization. Social Theory and Global Process. Sage, 1992.

Robertson, Roland. "Glocalization: Time-Space and Homogeneity-Heterogeneity." Global Modernities, edited by Mike Featherstone, et al. Sage, 1995, pp. 25-44. 
Schatzker, Mark. The Dorito Effect. The Surprising New Truth About Food and Flavor. Simon and Schuster, 2015.

Schiller, Nina Glick and Noel B. Salazar "Regimes of Mobility Across the Globe." Journal of Ethnic and Migration Studies, vol. 39, no. 2, 2013, pp. 183-200. https://doi.org/10.1080/13691 $83 X .2013 .723253$

Segers, Yves. Preface. Exploring the Food Chain: Food Production and Food Processing in Western Europe, 1850-1990, edited by Yves Seger, et al. Brepols, 2009, pp. 13-16.

Shephard, Sue. Pickled, Potted, and Canned. How the Art and Science of Food Preserving Changed the World. Simon and Schuster, 2000.

Shewfelt, Robert L. In Defense of Processed Food. It's Not Nearly as Bad as You Think. Springer, 2017.

Shove, Elizabeth. Comfort, Cleanliness and Convenience: The Social Organization of Normalcy. Berg, 2003.

Silva, Elizabeth B. Technology, Culture, Family. Influences on Home Life. Palgrave MacMillan, 2010.

Sinclair, Upton. The Jungle, edited by Clare Virginia Eby. Norton Critical Edition. W.W. Norton \& Co., 2003.

Taubes, Gary. The Case against Sugar. Alfred A. Knopf, 2016.

One World The Americas Everywhere
Touraine, Alain. ¿Cómo salir del neoliberalismo? Paidós, 1999.

Trubek, Amy. Haute Cuisine. How the French Invented the Culinary Profession. U of Pennsylvania P, 2000.

Tsing, Anna L. Friction. An Ethnography of Global Connection. Princeton UP, 2005.

Urry, John. Mobilities. Cambridge: Polity Press, 2007.

Vargas Cetina, Gabriela. Beautiful Politics of Music: Trova in Yucatán, Mexico. U of Alabama P, 2017.

Velázquez de Esquivel, Fanny. Prepare un bufet. Imprenta Manlio, 1970.

Wallerstein, Immanuel. The Modern World-System. Academic Publishers, 1974. 
Ward, Christina. American Advertising Cookbooks. How Corporations Taught Us to Love Spam ${ }^{T M}$, Bananas, and Jell-O ${ }^{T M}$. Process Media, 2019

Warner, Melanie. Pandora's Lunchbox. How Processed Food Took Over the American Meal. Scribner, 2013.

Williams, Simon N. and Marion Nestle, editors. Big Food. Critical Perspectives on the Global Growth of the Food and Beverage Industry. Routledge, 2016.

Winson, Anthony. The Industrial Diet. The Degradation of Food and the Struggle for Healthy Eating. New York UP, 2014.

Wolf, Eric. Europe and the People without History. U of California P, 1982.

Zayas Enríquez, Rafael de. El Estado de Yucatán. Su pasado, su presente, su porvenir. J.J. Little \& Ives Co., 1908.

Zeide, Anna. Canned. The Rise and Fall of Consumer Confidence in the American Food Industry. U of California P, 2018.

Steffan Igor Ayora-Díaz Universidad Autónoma de Yucatán Merida, Mexico 
